\title{
El movimiento como metáfora. Colocaciones con los verbos de movimiento venio e incido en latín
}

\section{Movement as Metaphor. Collocations with the Movement Verbs venio and incido in Latin}

\author{
María Isabel JiMÉNEZ MARTíNEZ \\ https://orcid.org/0000-0001-5232-0725 \\ Instituto de Investigaciones Filológicas, Universidad Nacional Autónoma de México, México \\ eirenez@hotmail.com
}

RESUMEN: Una de las características mejor conocidas de las colocaciones verbonominales es que uno de sus constituyentes, el colocativo, adopta un sentido metafórico adaptado al elemento principal de la construcción, la base. Sin embargo, poco se ha estudiado la relación entre las colocaciones y las metáforas que en ellas se dan. El objetivo de este trabajo es doble: por una parte, se propone ahondar en la estrecha relación entre metáfora y colocaciones; y, por otra, estudia una serie de metáforas que se activan en las colocaciones con los verbos latinos de movimiento venio e incido, en un corpus de datos representativo. Como veremos, las colocaciones con estos dos verbos están vinculadas a las metáforas orientacionales, presentes en una gran parte de lenguas del mundo, LOS ESTADOS SON CONTENEDORES Y EL INICIO DE UN EVENTO ES EL PUNTO FINAL DE UN MOVIMIENTO TÉLICO. Además, el verbo incido manifiesta en muchas de las construcciones en las que aparece un valor negativo, debido a la conceptualización en el mundo romano de la "caída", relacionada con la metáfora ARRIBA ES BUENO, ABAJO ES MALO.

Palabras Clave: metáfora, colocaciones, verbos de movimiento, sustantivos abstractos, latín

ABSTRACT: One of the best-known features of verb-noun collocations is that one of their constituents, the collocative, has a metaphorical sense adapted to the main element of the construction, the basis. However, there has been little attention to the relation between collocations and metaphors. Thus, the aim of this paper is double: on the one hand, to highlight the tight relationship between metaphor and collocations; and, on the other, to discuss some metaphors codded in collocations with the movement verbs venio and incido, from the analysis of a representative corpus. As we will see, collocations with these two verbs are 
connected to two orientational metaphors frequently used in a wide range of languages in the world: STATES ARE CONTAINERS and INCEPTIONS OF EVENTS ARE ENDPOINTS OF TELIC MOVEMENTS. Moreover, the verb incido has in many collocations a negative meaning because of the conceptualization of the "fall" in the Roman world, related to the UP IS GOOD, DOWN IS BAD metaphor.

KeYwords: Metaphor, Collocations, Movement Verbs, Abstract Nouns, Latin

ReCiBIDO: 22/10/2019 • ACEPTADO: 22/01/2020 • Versión FinAL: 21/06/2020

\section{INTRODUCCIÓN}

La relación, prácticamente inconsciente, que se genera en las metáforas entre realidades concretas y abstractas representa una de las estructuras cognitivas centrales para el ser humano, pues nos permite identificar, clasificar y hacer coherentes nuestras experiencias, $\mathrm{y}$, por consiguiente, pensar, razonar y hablar sobre ellas. Así lo vieron George Lakoff y Ronald Langacker en los años ochenta y lo plasmaron en distintas obras fundacionales para el estudio de la metáfora desde una perspectiva cognitiva. ${ }^{1}$ Desde este punto de vista, la metáfora es la manera de entender un concepto complejo a partir de otro más simple ${ }^{2}$ en ella, se presupone la existencia de un vínculo entre un 'dominio de origen' (que es literal y concreto) y un 'dominio de destino', el que se quiere entender (más abstracto).

Uno de los campos semánticos más recurrentes como 'dominio de origen' en las metáforas de la lengua latina $-\mathrm{y}$ de otras muchas lenguas del mundo - es el del movimiento, ${ }^{3}$ puesto que la posición y el desplazamiento en el espacio son algunas de nuestras fuentes primarias de conocimiento y comprensión del mundo, y, por tanto, nos ayudan a conceptualizar y entender no pocas realidades abstractas.

Esto es especialmente evidente en las colocaciones con sustantivos abstractos, del tipo de in spem adducere o morbus invadere, en las que los verbos adduco e invado, a pesar de tener un sentido originario espacial, "llevar" e "invadir" respectivamente, adquieren un nuevo valor metafórico: adduco pasa a significar 'causar' (causar esperanza) e invado se puede entender como 'empezar' (la enfermedad empieza).

Por tanto, el objetivo de este trabajo es analizar y entender la importancia de la metáfora en los distintos deslizamientos semánticos que se dan en el

\footnotetext{
${ }^{1}$ Gibbs y Steen 1997; Kövecses 2000, 2002; Lakoff y Johnson 1980; Lakoff 1987, 1993; Langacker 1987, 1991.

${ }^{2}$ Lakoff y Johnson 1980, p. 5.

${ }^{3}$ Fedriani 2011, 2018.
} 
seno de un gran número de colocaciones latinas en las que participan verbos de movimiento, algunos de ellos ya lexicalizados por completo.

El artículo se organizará como sigue: en la sección I se presentan algunas de las principales características de las metáforas y su relación con las construcciones fraseológicas; en la II se trata la importancia de las metáforas orientacionales en la concepción e interpretación de realidades abstractas; en el apartado III se analizan las metáforas presentes en dos tipos de colocaciones latinas formadas con los verbos venio e incido; y, por último, en la sección IV se recogen las conclusiones más relevantes de este trabajo.

\section{MetÁFORA y COLOCACIONES}

Generalmente, para que una metáfora sea exitosa, es importante que el dominio concreto de origen a partir del que pensamos lo abstracto de nuestras realidades esté íntimamente relacionado con nuestras experiencias físicas, con aquello que vivimos y experimentamos empíricamente, es decir, con nuestros objetos y acciones cotidianas, con nuestro cuerpo, con nuestra forma de relacionarnos con el medio o con el espacio en el que nos movemos.

$\mathrm{Y}$, puesto que nuestra estructura conceptual está íntimamente relacionada con las prácticas que proceden de nuestras experiencias físicas y materiales, nuestras producciones lingüísticas reflejan estas metáforas que surgen de lo físico. Vemos esto en el ejemplo de la frase de (1):

(1) illic ante omnia clandestina concocta sunt consilia ("Allí se cocinaron anteriormente todos los planes clandestinos", Liv., 40, 11, 3). ${ }^{4}$

Probablemente cuando un hablante del latín escuchaba la expresión concoquere consilia no pensaba en comida ni en la preparación de un plato, sino que entendía que se refería a "deliberar o trazar un plan". Y es que en latín, como en otras lenguas del mundo, ${ }^{5}$ el campo semántico de la "cocina" y de la "digestión" aporta un marco de referencia sistemático para hablar acerca de "meditar y deliberar ideas o planes". Por eso, en la lengua latina una idea bene cocta es una idea que se ha pensado con mucha dedicación y tiempo. Esto es posible gracias a que el pensamiento o la deliberación de ideas se concibe como un proceso que, del mismo modo que la cocina, requiere de un tiempo largo de preparación y cuidado.

\footnotetext{
${ }^{4}$ Todas las traducciones son propias.

${ }^{5}$ Palabra y comida, escribir y cocinar están rodeadas de un aire de familiaridad en multitud de lenguas, tal como queda de manifiesto, por poner solo algunos ejemplos, en los estudios realizados por Khajeh \& Imran (2012) para el persa, Rigotti (1999) para el italiano, Tomlinson (1986) para el inglés o Tsaknaki (2016) para el francés y el griego.
} 
Un aspecto especialmente interesante de la metáfora es que las representaciones conceptuales que en ella operan se encuentran almacenadas en la memoria a largo plazo de los hablantes, lo que permite que los miembros de una misma comunidad lingüística puedan entenderlas y reproducirlas sin ninguna dificultad, tal como proponen Gibbs y Steen: "This complex metaphoric representations are encoded as part of people's internal, long term memory sistems". ${ }^{6}$

Y no solo eso, sino que en muchas ocasiones estas representaciones metafóricas se almacenan en nuestra memoria en forma de frases (semi)fijas o construcciones fraseológicas. ${ }^{7}$ Esto es así porque, puesto que la metáfora consiste en expresar una realidad en términos de otra, cuando un hablante pretende evocar un sentido abstracto a partir de una palabra con sentido concreto, lo hace combinándola con un número reducido de posibles términos, que activan de manera inconsciente en el oyente o en el lector la interpretación metafórica. En esta misma línea, Lakoff habla de la relación entre metáfora y fraseología: "Those words activate a conventional mental image with associated knowledge commonplace in one's culture. There is a system of metaphors fixed in the mind that applies naturally, automatically, very quickly, and unconsciously to such knowledge, linking the knowledge of the image to the meaning of the idiom". 8

Por ejemplo, para que el verbo concoquere tenga un significado metafórico y no el literal debemos combinarlo con términos como consilium (consilium concoquere) o sermo (sermonem concoquere). Consilium y sermo nos ayudan, pues, a interpretar metafóricamente el verbo concoquere, a darle el sentido de "deliberar", que, en cualquier otro contexto, tendría el significado literal de "preparar los alimentos para comer". Podríamos decir, por tanto, que para entender el sentido metafórico de una palabra necesitamos encontrarla en un contexto predeterminado y reconocido por los hablantes que active su lectura metafórica.

Las colocaciones ${ }^{9}$ son un muy buen ejemplo de estas fórmulas que activan sentidos metafóricos en las palabras. De hecho, es común en la bibliografía (Cowie 1981; Corpas Pastor 1996; Bosque 2001; Koike 2001; etc.)

1997, p. 152.

${ }^{7}$ Glucksberg 2001.

${ }^{8}$ Lakoff 2014, p. 132.

${ }^{9}$ Las colocaciones, definidas por la Nueva Gramática de la Lengua Española como “combinaciones restringidas de voces cuya frecuencia de coaparición es muy elevada" (2009, p. 2614), son combinaciones de palabras casi automáticas que a los hablantes de la lengua nos "salen solas" y nos pasan prácticamente desapercibidas, pero que, si no se usan tal y como las conocemos, nos "suenan mal" y nos indican que quien habla no tiene un dominio pleno de nuestra lengua (Alonso Ramos 2004). Las colocaciones pueden tener diferentes estructuras: sustantivo + adjetivo (vino tinto), verbo + sustantivo (hacer un viaje), verbo + adverbio (cerrar herméticamente), sustantivo + sustantivo (ataque de celos), etc. (Koike 2001; Jiménez Martínez 2016). 
leer que una de las principales características de las colocaciones es que uno de sus dos constituyentes tiene una lectura figurada. ${ }^{10}$ Vemos esto, por ejemplo, en la colocación caeca mens de la siguiente frase:

(2) nec reputat caeca mens et tantum avaritiae intenta id ipsum scientia posse tutius fieri. ("No se da cuenta la mente ciega y atenta solamente a la codicia de que se puede lograr lo mismo con más seguridad con la ciencia”, Plin., $H N$., $2,118,7$.

En este caso, el constituyente central de la colocación, la 'base', 11 es mens, pues es el elemento autónomo y transparente semánticamente; y el constituyente subordinado a esta base, el 'colocativo', es el adjetivo caeca, cuyo significado se especializa en virtud de la base y resulta sensiblemente distinto del que tiene cuando se emplea aislado: aquí, caeca no se usa con su significado literal de "privado de la vista", sino que se utiliza con el sentido figurado de "confuso" o "turbado" (esquema 1).

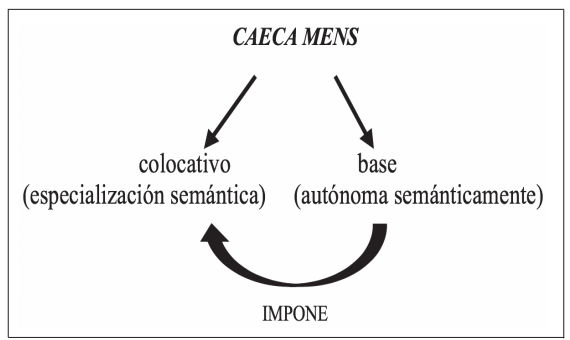

EsQuema 1: Características semánticas de los componentes de la colocación caeca mens

Esta lectura se debe a la manera en que se conceptualiza metafóricamente la base, mens: en Roma (y aún hoy en muchas lenguas del mundo), ${ }^{12}$ existe una metáfora que asocia la actividad mental con el sentido de la vista y con la luz. Según esta metáfora, ${ }^{13}$ entender un concepto es verlo con claridad,

${ }^{10}$ Corpas 1996, p. 66.

${ }^{11}$ Las colocaciones constan, generalmente, de dos elementos, cada uno de los cuales tiene una carga semántica distinta y se relaciona con el otro de forma asimétrica: uno de los elementos es autónomo semánticamente y regula la aparición del otro, es la 'base' de la colocación; el otro, que se conoce como 'colocativo', 'colocador' o 'colocante' está restringido y determinado semánticamente por la ‘base’ (Hausmann 1989; Írsula 1992 o Larreta Zulategui 2002, entre otros).

${ }^{12}$ Para una discusión en torno al alcance y a la universalidad de esta metáfora, cf. IbarretxeAntuñano 2008.

13 García Hernández (1976) estudia los verbos del campo semántico de la vista y asegura que "en su conjunto, la estructura dimensional del campo de 'ver' se adapta de modo proporcional a la de 'entender" ", lo que facilita múltiples deslizamientos de lexemas de este dominio léxico al ámbito de la percepción intelectual. También Torrego, en su estudio sobre los esquemas de complementación de los verbos de la vista en latín (2007), hace referencia a los usos de estos verbos como verbos cognitivos. 
mientras que estar en la oscuridad (tener un día nublado, no ver con claridad, etc.) nos lleva a la idea de no entender bien, de estar confundidos. De ahí que sustantivos como mens o iudicium propulsen en un adjetivo como caecus el sentido de "confuso, embotado o aturdido" (tener la mente embotada, el juicio confundido), o que existan expresiones como caligo mentis o caligo animi.

\section{METÁFORAS ORIENTACIONALES}

En la lengua latina, una gran cantidad de colocaciones ${ }^{14}$ están formadas con léxico que hace referencia al movimiento y a la posición en el espacio, siguiendo un esquema metafórico muy general y productivo translingüísticamente que recibe el nombre de "metáforas orientacionales". ${ }^{15}$ Estas son un conjunto de representaciones metafóricas que organizan un sistema global de conceptos en relación con la experiencia humana, imprescindible, del espacio: tanto del espacio en el que nos movemos y que ocupamos (nuestros dormitorios, nuestras casas, nuestra ciudad, etc.), como aquel que nos conforma en tanto que poseedores de un cuerpo material y delimitado (un cuerpo en el que metemos comida y bebida, que tiene órganos, cerebro, piel y corazón), lo que nos permite entender multitud de conceptos abstractos en forma de esquemas opositivos: dentro/fuera, arriba/abajo o delante/detrás.

Siendo tan importante para los seres humanos la percepción del espacio físico y su posición y movimientos en él, no es de extrañar que este sea una de las fuentes principales para entender, interpretar y hablar de nuestras realidades abstractas. De hecho, tal como afirma Short (2008), la metáfora orientacional es un "esquema fundacional" básico en nuestra comprensión e interacción con el mundo. Prueba de ello es que si analizamos el vocabulario que utilizamos - y que se usa en la lengua latina - para hablar, por ejemplo, de actividades mentales, fisiológicas o de las emociones, nos damos cuenta de que recurrimos sistemáticamente al léxico del espacio físico. Vemos esto en los siguientes ejemplos latinos con el sustantivo morbus:

(3) sic illi in morbum et incidunt tardius et recreantur ocius, hebetes non item ("así, [los inteligentes] caen en la enfermedad más tarde y se recuperan más rápido, mientras que a los toscos no les sucede lo mismo", Cic., Tusc., 4, 32, 12).

(4) Tu quoniam quartana cares et novum morbum removisti sed etiam gravedinem, te vegetum nobis in Graecia siste ("Tú, puesto que ya has salido de la cuartana y has eliminado esta nueva enfermedad, pero también el resfriado, espérame lleno de salud en Grecia", Cic., Att., 10, 16, 6, 1).

\footnotetext{
${ }^{14}$ Para un análisis sobre las colocaciones en latín, cf. Baños 2016 y 2018.

${ }^{15}$ Lakoff y Johnson 1980.
} 
(5) Quo modo autem in corpore est morbus, est aegrotatio, est vitium, sic in animo ("Ahora bien, del mismo modo que en el cuerpo hay enfermedad, tristeza y vicio, así también en el alma”, Cic., Tusc., 4, 28, 11).

Sin duda, en estas colocaciones y en otras similares, los diferentes momentos y las diferentes reacciones que suscitan las enfermedades se expresan metafóricamente en términos de movimiento y posición en el espacio físico. Y es que en todas ellas se activa la macro-metáfora, muy general y esquemática, LOS EVENTOS SON MOVIMIENTOS. ${ }^{16}$ Esta se basa en un dominio de origen (el del movimiento físico) muy amplio y rico semánticamente, que puede ser concretado de múltiples y variadas formas, y puede representar un amplio rango de procesos y situaciones: ${ }^{17}$ por ejemplo, en (3) el verbo incido no significa "perder el equilibrio y caer a una superficie", sino "empezar a sufrir una enfermedad"; del mismo modo, removeo en (4) no se refiere a la acción de "mover hacia atrás", sino que, a partir de este significado espacial original, se desarrolla un sentido figurado que viene a significar "eliminar" o "curar" cuando se une a sustantivos del campo semántico de las enfermedades. Por último, in corpore est morbus (5) no indica que la enfermedad está ocupando el espacio físico real del cuerpo, sino que alguien siente la enfermedad en su cuerpo.

A continuación, analizaremos distintas metáforas que se pueden concebir dentro de esta macro-metáfora orientacional en la lengua latina.

\section{MOVIMIENTO, COLOCACIÓN Y METÁFORA EN LATÍN: VENIO E INCIDO}

En vista de la importancia de las colocaciones formadas sobre la base de la metáfora LOS EVENTOS SON MOVIMIENTOS, decidimos analizar algunas de las colocaciones verbo-nominales en las que participan dos verbos de movimiento muy frecuentes en latín: los verbos intransitivos venio e incido, en sus usos con un sintagma preposicional in / ad + un sustantivo abstracto en caso acusativo, como in mentem venire (6) e in amorem incidere (7), respectivamente:

(6) itaque me etiam admonuisti ut gauderem; nam mihi in mentem non venerat ("Y así también me moviste a mí a alegrarme, pues no se me había venido a la mente", Cic., Att., 5, 19, 3).

\footnotetext{
${ }^{16}$ Esta macro-metáfora se fundamenta en la idea de que los eventos en general (las acciones, las actividades, los cambios de estado, etc.) tienden a entenderse metafóricamente en un gran número de lenguas del mundo en términos de movimiento físico, fuerza y espacio (Kövecses 2000, p. 52).

${ }^{17}$ Kövecses 2002, p. 33.
} 
(7) nemo potest uno aspectu neque praeteriens in amorem incidere ("nadie puede enamorarse [caer en el amor $]^{18}$ a primera vista ni de pasada", Cic., Inv. Rhet., $1,80,15)$.

Llevamos a cabo este estudio en un corpus que recoge todas las apariciones de ambos verbos desde Plauto hasta Tácito en la base de datos del Packard Humanities Institute para el latín, ${ }^{19}$ con el objetivo no solo de entender las lecturas metafóricas que se activan en ellos, sino también las relaciones que establecen con otras colocaciones.

\section{III.1 Venio: el inicio de un evento es el punto final de un movimiento télico}

Venio es un verbo de movimiento, cuya estructura argumental ${ }^{20}$ prototípica puede representarse mediante el siguiente marco predicativo ${ }^{21}$ (8) e ilustrarse con el ejemplo de (9):

(8) venio $_{\mathrm{V}}[/ \text { animado/ }]_{\text {Agente }}{ }^{22}[/ \text { lugar/ }]_{\text {Dirección }}$

(9) P. Licinius in Bruttios ad duos exercitus consulares venit ("Publio Licinio fue al Brucio donde estaban los dos ejércitos consulares", Liv., 28, 46, 2).

Este esquema (8) nos muestra que venio es un verbo intransitivo que cuenta con dos argumentos obligatorios: ${ }^{23}$ un sujeto-Agente, que es la entidad que se desplaza en el espacio y tiende a expresarse en forma de un ser animado y consciente - como $P$. Licinius en el ejemplo de (9)-; y un segundo argumento que indica la dirección hacia la que el sujeto se mueve y se actualiza generalmente mediante los sintagmas preposicionales in + acusativo - in Bruttios (9) - y ad + acusativo - ad duos exercitus consulares

${ }^{18}$ Entre paréntesis cuadrados proponemos una lectura literal de la colocación.

${ }^{19}$ En nuestro corpus, el verbo venio conforma 41 colocaciones verbo-nominales atestiguadas en un total de 576 ejemplos, mientras que con el verbo incido hemos encontrado 88 colocaciones distribuidas en 197 apariciones. Estos datos son producto de una colaboración con el doctor J. M. Baños.

${ }^{20}$ En este trabajo seguimos los principios teóricos y metodológicos de la Gramática Funcional (Dik 1997) para describir la estructura sintáctica y semántica de los verbos. Para ello, acudimos a los 'marcos predicativos', formalizaciones que recogen las propiedades combinatorias y el significado que subyace a todos los usos gramaticales de un determinado verbo.

${ }^{21}$ Para la formalización del marco predicativo de venio nos basamos en Cabrillana 1997.

${ }^{22}$ Para las funciones semánticas, cf. Torrego-De la Villa 2009, pp. 71 ss.).

${ }^{23}$ Cabrillana (1997) muestra una serie de ejemplos del verbo venio en los que la dirección no se expresa léxicamente y tampoco puede ser recuperada por el contexto, son los usos absolutos del verbo. Se trata de casos como "postquam dies commitiorum venit" ("Cuando llegó el día de las elecciones", Sall., Cat., 26,5), que se distinguen de los usos prototípicos de venio por tener un sujeto no animado (dies, idus, etc.). 
(9) - o en acusativo sin preposición, cuando se trata del nombre de un lugar menor. $^{24}$

La presencia de un argumento que expresa la dirección del movimiento hace de venio un verbo télico (con un final delimitado), aspecto que es imprescindible para entender sus realizaciones metafóricas. Y es que, cuando venio actualiza su segundo argumento con sustantivos abstractos en lugar de hacerlo con nombres de lugares, se pone en juego una metáfora muy productiva en las lenguas del mundo que recibe el nombre de LOS ESTADOS SON CONTENEDOREs ${ }^{25}$ como podemos ver en los siguientes ejemplos (10 a 12):

(10) quem simulatque oppidani conspexerunt atque in spem auxilii venerunt, cla more sublato arma capere, portas claudere, murum complere coeperunt ("Pero en cuanto los sitiados la vieron y nació en ellos la esperanza de socorro [llegaron a la esperanza de socorro], lanzaron el grito de guerra y empezaron a tomar las armas, a cerrar las puertas, a ocupar la muralla", Caes., Gall., 7, 12, 5).

(11) $[\ldots]$ ut iam non solum hostibus in contemptionem Sabinus veniret, sed etiam nostrorum militum vocibus nonnihil carperetur ("de esta forma Sabino no solo empezó a ser despreciado por los enemigos [Sabino llegó al desprecio], sino que también era criticado en algunos comentarios de nuestros soldados", Caes., Gall., 3, 17, 5).

(12) tu non vides unius inportunitate et superbia Tarquinii nomen huic populo in odium venisse regium? ("ipero no ves que el nombre del rey se ha hecho odioso para nuestro pueblo [el nombre del rey ha llegado al odio para nuestro pueblo] por culpa de la crueldad y la soberbia de un solo Tarquinio?", Cic., Rep., 1, 62).

En esta metáfora, los estados mentales abstractos, como spem (10), contemptionem (11) y odium (12), son interpretados como espacios limitados de la realidad material, en los que los seres humanos, entendidos como entidades concretas, pueden estar, entrar o salir: esto es evidente, por ejemplo, en (10), donde la esperanza (spem) se expresa lingüísticamente como un recipiente al que los sitiados (oppidani) pueden llegar (venerunt), tal como muestra el esquema (2).

Pero el verbo venio no es el único susceptible de formar colocaciones basadas en la metáfora LOS ESTADOS SON CONTENEDORES. Al contrario, este es un esquema metafórico muy productivo en latín y en muchas otras lenguas del mundo ${ }^{26}$ para hablar, sobre todo, acerca de estados mentales abstractos, pues permite expresar en términos de entidades concretas que existen en

\footnotetext{
${ }^{24}$ Cabrillana 1997, p. 119. Estas no son las únicas posibilidades de expresión del segundo argumento del verbo venio, Cabrillana recoge también la presencia de adverbios y dativos.

25 Kövecses 2000; Lakoff y Johnson 1980; Sandstörm 2006.

${ }^{26}$ Fedriani 2011, pp. 314 ss.
} 


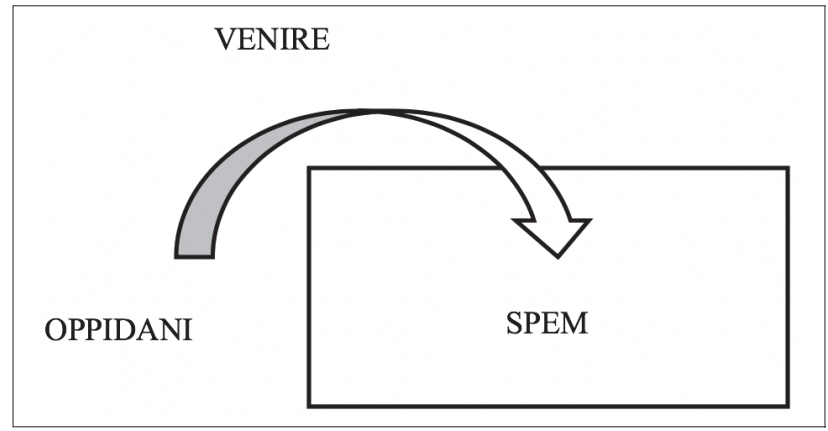

Esquema 2: Representación gráfica de la Metáfora del Contenedor basada en el ejemplo (10)

nuestro entorno material más cercano (objetos y recipientes) conceptos complejos de nuestro mundo psicológico y emocional. Los siguientes ejemplos son una buena muestra de ello:

(13) quam conveniens esse propter Q. Fabium civitatem in laetitia victoria supplicationibus ac gratulationibus esse [...] ("qué coherente resultaba que mientras la ciudad estaba inmersa en la alegría, la victoria, las plegarias y las acciones de gracias por obra de Quinto Fabio, [...]”, Liv., 8, 33, 20).

(14) ita est, mi Lucili, cito accedimus opinioni, non coarguimus illa quae nos in metum adducunt "así es, querido Lucilio, creemos fácilmente en las opiniones; no rebatimos aquellas cosas que nos llevan a sentir miedo", Sen., Ep., $13,8)$.

En el ejemplo (13), la manera que tiene Livio de expresar que los habitantes de la ciudad sienten alegría es a partir de la ubicación en un espacio metafórico: las personas que viven en la ciudad (civitatem) están ubicadas (esse) dentro de un contenedor, la alegría (in laetitia). De un modo similar, en (14), Séneca utiliza esta misma metáfora, ahora con el verbo de movimiento adduco, para referirse a algo que causa miedo: aquellas cosas (illa) conducen (adducunt) a unas personas (nos) - pensadas como objetos que pueden manipularse y moverse-, a un recipiente, el miedo (in metum).

Frente a estas colocaciones con sum y con adduco, las colocaciones con el verbo venio tienen valor incoativo, ${ }^{27}$ es decir, indican el inicio del evento predicado por el sustantivo: in spem venire expresa la idea de "empezar

${ }^{27}$ Los verbos de las colocaciones pueden aportar, como se observa en estos ejemplos, significado de tipo aspectual (indican el inicio, el desarrollo o la conclusión de un evento), diatético (muestran el evento desde una perspectiva causativa o pasiva) o intensivo (denotan el grado mayor o menor en el que se da un evento). Algunos estudios acerca de este aspecto de las colocaciones son Baños 2014, M. Gross 1998 o G. Gross 2004. 
a sentir la esperanza", del mismo modo que in contemptionem venire significa, grosso modo, "empezar a ser despreciado" e in odium venire, "empezar a ser odiado". En estas colocaciones, encontramos, pues, una nueva metáfora que se conoce como EL INICIO DE UN EVENTO ES EL PUNTO FINAL DE UN MOVIMIENTO TÉLICO, ${ }^{28}$ y puede representarse esquemáticamente como sigue (esquema 3):

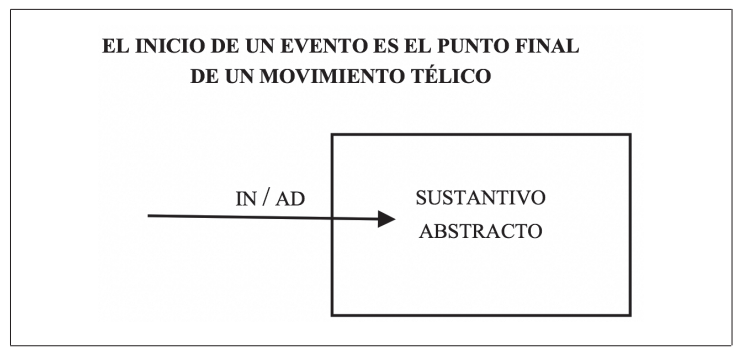

Esquema 3: Representación gráfica de la metáfora EL INICIO DE UN EVENTO ES EL PUNTO FINAL DE UN MOVIMIENTO TÉLICO

Como hemos visto, venio es un verbo que hace referencia a un movimiento télico puesto que está orientado hacia una dirección determinada que implica el fin del movimiento. En los casos en los que esta dirección final es un sustantivo abstracto, el punto de llegada del movimiento metafórico puede entenderse, también, como el inicio de la situación, proceso, acción o evento que indica el sustantivo. ${ }^{29}$

Por último, recogemos en el esquema 4 los veinte sustantivos más frecuentes que forman colocaciones con el verbo venio:

venio in / ad + acusativo

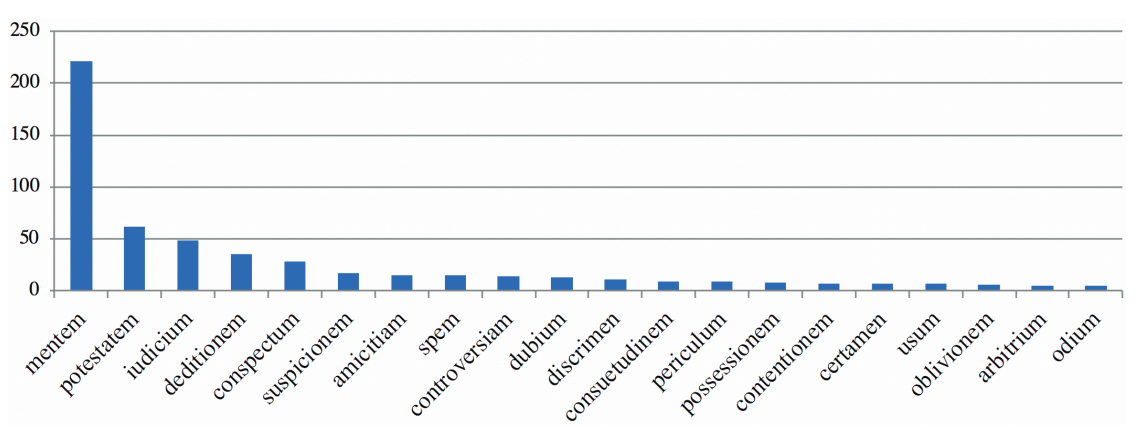

EsQuema 4: Sustantivos abstractos más frecuentes con el verbo venio

\footnotetext{
${ }^{28}$ Fedriani 2011, pp. 314 ss.

${ }^{29}$ Fedriani 2011, 2016; Rosen 1981.
} 
De ellas, es especialmente interesante in mentem venire, con mucho la más frecuente de nuestro corpus (221 ejemplos) y presente aún hoy en la lengua española, "venir a la mente" o "venir a la cabeza". En esta colocación, además de la metáfora EL INICIO DE UN EVENTO ES EL PUNTO FINAL DE UN MOVIMIENTO TÉLICO, se activa una metonimia que identifica la mente con el proceso cognitivo de pensar, cavilar u ocurrirse algo a alguien: in mentem venire podría parafrasearse por "acabarse de venir a la cabeza / de ocurrir algo", como podemos comprobar en ejemplos como el que sigue:

(15) Leon. Attatae, modo hercle in mentem venit, nimis vellem habere perticam ("Le. - ¡Eh!, se me acaba de venir a la cabeza una cosa. ¡Si tuviera ahora mismo un palo!", Plaut., Asin., 588).

\section{III.2 Incido: el inicio de una situación negativa es una caída}

El verbo incido es también un verbo intransitivo que denota el movimiento de una entidad A, el sujeto, hacia una entidad B, la dirección final de la caída, tal como vemos en la formalización de su marco predicativo (16) y en el ejemplo (17):

(16) incido $\mathrm{v}[/ \text {-control } /]_{\text {Afectado }}[/ \text { lugar } /]_{\text {Dirección }}$

(17) Ipse rex in rapidissimos vertices incidit, quibus intorta navis obliqua et gubernaculi impatiens agebatur ("El mismo rey cayó en unos remolinos vertiginosos que, zarandeando la nave, la pusieron de costado, sin obedecer ya al timonel", Curt., 9, 4, 11,5).

La principal característica de este verbo es que predica un movimiento incontrolado, ${ }^{30}$ en el que su sujeto, que puede ser tanto una entidad animada como inanimada, ${ }^{31}$ sufre la acción expresada por incido, por eso le otorgamos la función semántica de Afectado: ${ }^{32}$ en la oración de (17) el rey (ipse rex), privado por completo del control de su cuerpo, es arrastrado a unos enormes remolinos marinos - in rapidissimos vertices - que prácticamente hacen naufragar la nave en la que navega. Este aspecto, la falta de control del movimiento, es, como veremos, imprescindible en la conceptualización metafórica de las colocaciones en las que aparece este verbo.

Cuando el segundo argumento de incido, en lugar de ser un sustantivo espacial -vertices en (17) -, es un sustantivo abstracto, como amor o miseria, se conforman colocaciones que activan sentidos metafóricos muy

\footnotetext{
${ }^{30}$ Para el verbo simple cado, cf. Pinkster 2010, p. 39.

${ }^{31}$ Macías 1994,p. 25.

32 Para la función semántica de Afectado, cf. Dowty 1991.
} 
cercanos a los que se presentan en las colocaciones que hemos analizado con venio (con algunas particularidades que comentaremos en detalle a continuación), como podemos ver en los siguientes ejemplos:

(18) In amorem filiae istius incidi ("Me enamoré [caí en el amor] de su hija", Sen., Con.ex., 3, 5, 1, 16).

(19) non faciam ut enumerem miserias omnis in quas incidi ("No intentaré enumerar todas las miserias en las que he caído", Cic., Att., 3, 7, 2).

En primer lugar, la presencia obligatoria de un sintagma preposicional introducido por las preposiciones ad o in + acusativo indicando la dirección final del movimiento nos lleva a pensar en la existencia de un recipiente en el que cae el sujeto del verbo, de nuevo, a partir de la metáfora LOS ESTADOS SON CONTENEDORES. En (18), por ejemplo, el sujeto elíptico (ego) se hunde en un contenedor, el amor (in amorem), como muestra el siguiente esquema:

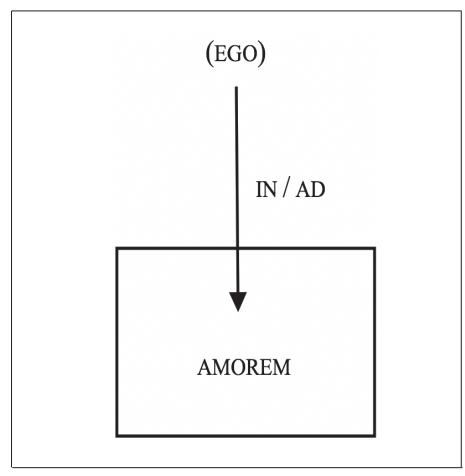

Esquema 5: Representación gráfica de la Metáfora del Contenedor basada en el ejemplo (18)

Además, igual que sucede con el verbo venio, las colocaciones con incido son expresiones incoativas, pues indican el inicio de la situación predicada por el sustantivo que ocupa la casilla del segundo argumento del verbo: in amorem incidere expresa la idea de "enamorarse" o "empezar a sentir amor", igual que in miserias incidere significa "empezar a sufrir la miseria". Con este verbo se activa, también, la metáfora EL INICIO DE UN EVENTO ES EL PUNTO FINAL DE UN MOVIMIENTO TÉLICO.

Sin embargo, el verbo incido participa en colocaciones con ciertas restricciones semánticas que lo distinguen del verbo venio y que podemos percibir al observar el esquema 6, que recoge los sustantivos que se combinan más frecuentemente con este verbo en nuestro corpus: 
incido in / ad + acusativo

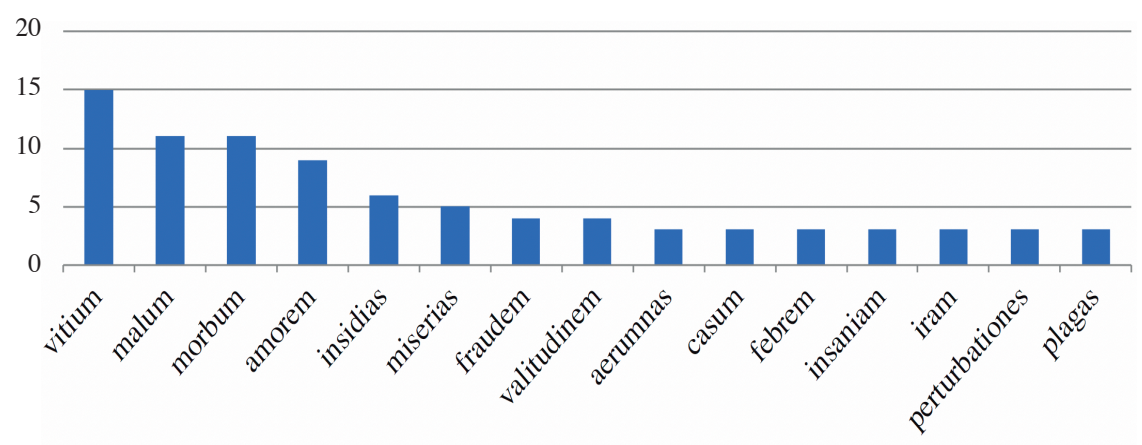

Esquema 6: Sustantivos abstractos más frecuentes con el verbo incido

La primera lectura de este esquema, la más evidente, es que el verbo incido tiende a formar colocaciones con sustantivos de polaridad negativa: vitium, malum, morbum, insidias, miserias, fraudem, etc. ${ }^{33}$ De ahí que le demos a la metáfora que subyace a estas colocaciones el nombre de EL INICIO DE UNA SITUACIÓN NEGATIVA ES UNA CAÍDA.

En este caso proponemos que se ha guardado en la memoria de los hablantes no tanto una colocación en concreto sino el vínculo entre el verbo incido y la idea de un evento negativo, lo que ha permitido tanto la creación de múltiples colocaciones con connotaciones negativas, como la posibilidad de comprensión y descodificación de estas por parte de los hablantes, aunque fuera la primera vez que las escucharan.

Este proceso ha sido posible gracias a la potencia de la metáfora que relacionamos con el verbo incido. Del mismo modo que sucede con el verbo español "caer", se puede decir que entre las propiedades que definen el significado de incido se encuentran "movimiento descendiente" y "sin control". Estos dos elementos, "abajo" y "sin control", se vinculan en la cultura occidental con lo negativo y ambos, a su vez, se relacionan con la vivencia de nuestro propio cuerpo: los seres humanos estamos conformados física-

${ }^{33}$ Aunque el verbo incido se combina generalmente con sustantivos negativos, no siempre es así. El ejemplo de in amorem incidere es ilustrativo al respecto: amor es un sustantivo o bien de polaridad positiva - lo que explicaría combinaciones como amore frui (Cic., Att., 3, 17, 3; Prop., 2, 1, 48; Tib., 1, 5, 7; etc.) o dulcis amor (Catull., 64, 120; 66, 6; 78, 3; Verg., Georg., 3, 291-292) - o, en cualquier caso, de polaridad neutra. Una colocación como in amorem incidere solo puede entenderse como el fruto de una doble metáfora. En efecto, en el origen de esta colocación subyace la metáfora estructural EL AMOR ES UNA ENFERMEDAD (Bacchini 2008; Cabello Pino 2009; Kövecses 2000; entre otros). La existencia de esta metáfora posibilita que el amor pueda heredar las metáforas, y por ende las colocaciones a que dan origen estas, asociadas a la enfermedad, entre ellas, in morbum incidere. Tenemos, por tanto, una primera metáfora estructural que posibilita la segunda metáfora, en este caso orientacional. 
mente a partir de un eje vertical, en el que la parte más alta la ocupa nuestra cabeza, la parte más valiosa, y la que está más abajo la ocupan los pies, en contacto con el suelo, de connotaciones negativas. Este es uno de los motivos de que percibamos lo que está arriba como positivo y lo que está abajo como negativo - según la metáfora ARRIBA ES BUENO, ABAJO ES MALO-,34 y de una innumerable cantidad de colocaciones (estatus alto, clase baja, la cima del éxito). Por su parte, la idea negativa que subyace de la pérdida de control también se puede explicar a partir de nuestro cuerpo: ${ }^{35}$ el eje vertical que conforma el cuerpo humano se mantiene así, vertical, gracias al equilibrio que establecemos entre las distintas fuerzas físicas que lo condicionan, de ahí que lo equilibrado (una dieta equilibrada, una persona equilibrada) sea bueno y lo desequilibrado lo entendamos como malo (a partir de la metáfora EL EQUILIBRIO ES BUENO, EL DESEQUILIBRIO ES MALO).

\section{CONCLUSIONES}

En este trabajo nos hemos centrado en la relación entre metáfora y colocaciones en la lengua latina; en concreto, hemos estudiado las metáforas que se activan en las colocaciones verbo-nominales del latín formadas con verbos de movimiento y sustantivos abstractos, del tipo de in spem venire e in amorem incidere.

Como vimos en la sección I, uno de los rasgos semánticos básicos de las colocaciones es la lectura metafórica de uno de sus elementos, el colocativo, que adapta su significado al de la base: en la colocación morbus invadere por ejemplo, el verbo invadere presenta el sentido figurado de "empezar", en lugar del literal "irrumpir o entrar por la fuerza", en combinación con un sustantivo como morbus. A este respecto, hemos propuesto que las expresiones metafóricas, que se guardan en la memoria como un todo unitario, muchas veces lo hacen en forma de construcciones semifraseológicas, puesto que para entender el sentido metafórico de una palabra (invadere) necesitamos encontrarla en un contexto predeterminado y reconocido por los hablantes que active su lectura metafórica (morbus).

Por otra parte, y en vista de la enorme presencia en la lengua latina de colocaciones formadas con verbos de movimiento - por ser este una de las fuentes primarias de comprensión del mundo-(II), decidimos analizar las colocaciones en las que participan dos verbos muy productivos, venio e incido, cuando aparecen junto con las preposiciones in / ad + acusativo (III). Hemos podido ver que las construcciones con ambos verbos, por ser télicos,

\footnotetext{
${ }^{34}$ Casasanto 2009; Glenberg y Kaschak 2002; Lakoff y Johnson 1999; Shapiro 2011, etc.

35 Johnson 1987.
} 
intransitivos y con un argumento direccional que indica el fin del movimiento predicado, codifican una metáfora muy común translingüísticamente que recibe el nombre de LOS ESTADOS SON CONTENEDORES, que entiende que los humanos, percibidos como objetos que se pueden manipular y desplazar, pueden llegar, entrar y salir de las situaciones abstractas en las que se ven involucrados.

En particular, las colocaciones con el verbo venio (III.1), como in spem venire, ponen en juego una metáfora conocida como EL INICIO DE UNA SITUACIÓN ES EL PUNTO FINAL DE UN MOVIMIENTO TÉLICO, pues en ellas se entiende el punto de llegada del movimiento metafórico como el inicio de la situación, proceso, acción o evento que indica el sustantivo. Así pues, in spem venire podría traducirse como "empezar a sentir esperanza".

Las colocaciones con el verbo incido (III.2), por último, comparten las mismas representaciones metafóricas que las que se activan con venio, pero incluyen un matiz que tiene que ver con la polaridad semántica de los sustantivos con los que se combina: el verbo incido tiende a seleccionar mayoritariamente nombres de eventos negativos, como miserias, vitium o fraudem, de ahí que hayamos propuesto la metáfora EL INICIO DE UNA SITUACIÓN NEGATIVA ES UNA CAÍDA.

\section{BIBLIOGRAFÍA}

\section{Fuentes antiguas}

Classical Latin Texts, Packard Humanities Institute (PHI), California, https://latin. packhum.org/ (22/10/2019).

\section{Fuentes modernas}

Alonso Ramos, Margarita, Las construcciones con verbo soporte, Madrid, Visor, 2004.

Bacchini, Fabio, "Love as sickness. The analogy to put the test", Medische Antropologie, 20/1, 2008, pp. 13-26.

Baños, José Miguel, "Construcciones con verbo soporte, extensiones y elecciones preferentes: bellum parare, suscipere, trahere, conficere", Boletín de la Sociedad de Estudios Latinos, 1, 2014, pp. 5-11.

BAÑos, José Miguel, "Las construcciones con verbo soporte en latín: sintaxis y semántica”, en Esperança Borrell \& Óscar de la Cruz (eds.), Omnia mutantur, II, Barcelona, Universitat de Barcelona Edicions, 2016, pp. 15-39.

BAÑos, José Miguel, "Las construcciones con verbo soporte en latín: una perspectiva diacrónica", en Colette Bodelot \& Olga Spevak (eds.), Les constructions 
à verbe support en latin, Toulouse, Presses Universitaires Blaise Pascal, 2018, pp. 21-51.

Bosque, Ignacio, "Bases para un diccionario de restricciones léxicas", Moenia, 7 , 2001, pp. 11-52.

Cabello Pino, Manuel, "La enfermedad de amor en Lucrecio y Catulo. Dos visiones opuestas de un mismo tópico literario", Tonos digital. Revista de estudios filológicos, 18, 2009, http://www.tonosdigital.es/ojs/index.php/tonos/article/view/ $342(21 / 06 / 2020)$.

Cabrillana, Concepción, "Complementos direccionales en el marco predicativo de venio", Minerva, 11, 1997, pp. 117-137.

Casasanto, Daniel, "Embodiment of abstract concepts: Good and bad in right- and left-handers", Journal of Experimental Psychology: General, 138/3, 2009, pp. 351-367.

Corpas, Gloria, Manual de fraseología española, Madrid, Gredos, 1996.

CowIE, Anthony Paul, "The treatment of collocations and idioms in learner's dictionaries", Applied Linguistics, 2/3, 1981, pp. 223-235.

DIK, Simon, The Theory of Functional Grammar, Part I. The Structure of the Clause, Berlin, Mouton de Gruyter, 1997.

Dowty, David, “Thematic Proto-Roles and Argument Selection”, Language, 67, 1991, pp. 547-619.

Fedriani, Chiara, "Experiential Metaphors in Latin: feelings were containers, movements and things possessed", Transactions of the Philological Society, 109/3, 2011, pp. 307-326.

FEDRIANI, Chiara, "Ontological and orientational metaphors in Latin. Evidence from the semantics of feelings and emotions", in William M. Short (ed.), Embodiment in Latin Semantics, Amsterdam/Philadelphia, John Benjamins Publishing Company, 2016, pp. 115-140.

García Hernández, Benjamín, El campo semántico de «ver» en la lengua latina. Estudio estructural, Salamanca, Universidad de Salamanca, 1976.

GibBs, Raymond W. \& Gerard J. STEEN, Metaphor in Cognitive Linguistics. Selected papers from the 5th International Cognitive Linguistics Conference, Amsterdam/Philadelphia, John Benjamins Publishing Company, 1997.

Glenberg, Arthur \& Michael P. KaschaK, "Grounding language in action", Psychonomic Bulletin and Review, 9, 2002, pp. 558-565.

Glucksberg, Sam, Understanding figurative language: from Metaphor to Idioms, Oxford, Oxford University Press (Oxford Psychology Series, 36), 2001.

Gross, Gaston, "Pour un Beschellere des prédicats nominaux", en Gaston Gross \& Sophie Pontonx (eds.), Verbes supports: nouvel état des lieux, Amsterdam/Philadelphia, John Benjamins Publishing Company, 2004, pp. 343-358.

Gross, Maurice, "La function sémantique des verbes supports", Travaux de Linguistique, 37, 1998, pp. 25-46.

Hausmann, Franz J., "Le dictionnaire de collocations", en Franz J. Hausmann et al. (eds.), Wörtebürcher. Dictionaries. Dictionnaires. Ein internationales Handbuch zur Lexikographie. An International Encyclopedia of Lexicography, Berlin/New York, Walter de Gruyter, 1989, pp. 1010-1019. 
IbarRetXe-Antuñano, Iraide, "Vision Metaphors for the Intellect: are they really cross-linguistic?", Atlantis. Journal of the Association of Anglo-American Studies, 30/1, 2008, pp. 15-33.

Írsula, Jesús, "Colocaciones sustantivo-verbo", en Gerd Wotjak (ed.), Estudios de fraseología y fraseografía del español actual, Frankfurt/Madrid, Iberoamericana, 1992, pp. 159-167.

JimÉnez Martínez, María Isabel, Colocaciones y verbos soporte en latín: semántica y sintaxis del verbo pono, tesis de doctorado inédita, Madrid, Universidad Complutense de Madrid, 2016.

Johnson, Mark, The Body in the Mind: The Bodily Basis of Meaning, Imagination, and Reason, Chicago, University of Chicago Press, 1987.

KhaJeH, Zahra \& ImRAn Ho Abdullah, a GEMA Online Journal of Language Studies, 12/1, 2012, pp. 69-87.

Korke, Kazumi, Colocaciones léxicas en el español actual: estudio formal y léxico-semántico, Madrid, Universidad de Alcalá de Henares, 2001.

KöveCSES, Zoltan, Metaphor and emotion: language, culture and body in human feeling, New York, Cambridge University Press, 2000.

Kövecses, Zoltan, Metaphor: A practical Introduction, Oxford, Oxford University Press, 2002.

LAKOFF, George, Women, fire and dangerous things: What categories reveal about the mind, Chicago, University of Chicago Press, 1987.

LAKOFF, George, "The contemporary theory of metaphor", in Andrew Ortony (ed.), Metaphor and thought, New York, Cambridge University Press, 1993, pp. 202251.

LAKOFF, George, "Mapping the brains metaphor circuitry: Metaphorical thought in everyday reason", Frontiers in human neuroscience, 8, 2014, https://www.ncbi. nlm.nih.gov/pmc/articles/PMC4267278/ (21/06/2020).

LaKoff, George \& Mark Johnson, Metaphors we live by, Chicago, University of Chicago Press, 1980.

Lakoff, George \& Mark Johnson, Philosophy in the Flesh: The Embodied Mind and its Challenge to Western Thought, New York, Basic Books, 1999.

LANGaCKer, Ronald, Foundations of Cognitive Grammar. Vol. I. Theoretical prerequisites, California, Standford University Press, 1987.

LANGacker, Ronald, Foundations of Cognitive Grammar Vol. II. Descriptive Application, California, Stanford University Press, 1991.

Larreta Zulategui, Juan Pablo, "En torno a la semántica de las colocaciones fraseológicas", Estudios de Lingüística, 16, 2002, pp. 121-138.

Macías Villalobos, Cristóbal, "Los verbos cadere y caedere en la Vulgata latina", Analecta malacitana, 17/1, 1994, pp. 25-52.

PInKster, Harm, "The use of the dative with Latin compounds", STUF - Language Typology and Universals / Sprachtypologie und Universalienforschung, 63, 2010, pp. 32-43.

Real Academia Española y Asociación de Academias de la Lengua Española, Nueva gramática de la lengua española. Morfología. Sintaxis, 2 vols., Madrid, Espasa Libros, 2009. 
Rigotti, Francesca, La filosofia in cucina. Piccola critica della ragion culinaria, Bologna, Il Mulino, 1999.

Rosen, Hannah, Studies in the Syntax of the Verbal Noun in Early Latin, Münich, Fink, 1981.

SANDSTÖRM, Karin, When motion becomes emotion: A study of emotion metaphors derived from motion verbs, Lulea, Lulea University of Technology, 2006.

SHAPIRO, Lawrence, Embodied Cognition, London, Routledge, 2011.

SHorT, William M., "Thinking places, placing thoughts. Spatial Metaphors of mental activity in Roman Culture", I quaderni del ramo d'oro online, 1, 2008, pp. 106129. http://www.qro.unisi.it/frontend/sites/default/files/Thinking_Places,_Placing_Thoughts.pdf (21/06/2020).

Tombinson, Barbara, "Cooking, mining, gardening, hunting: Metaphorical stories writers tell about their composing processes", Metaphor and Symbolic Activity, 1, 1986, pp. 57-79.

Torrego, Esperanza, “Esquemas de complementación de los verbos de 'ver' en latín", en Esperanza Torrego et al. (eds.), Praedicativa II: esquemas de complementación verbal en griego antiguo y en latín, Zaragoza, Universidad de Zaragoza, 2007, pp. 233-264.

Torrego, Esperanza \& Jesús DE LA VILla, "La oración independiente: concepto, estructura, constituyentes y niveles”, en José Miguel Baños (coord.), Sintaxis del Latín Clásico, Madrid, Liceus, 2009, pp. 55-82.

TsaKnaKi, Olympia, "Cooking verbs and metaphor. Contrastive study of Greek and French", Selected Papers of the $21^{\text {st }}$ International Symposium on Theoretical and Applied Linguistics (ISTAL21), 2016, pp. 458-472.

María Isabel Jiménez Martínez es doctora en Filología Clásica por la Universidad Complutense de Madrid. En el curso 2017-2018 disfrutó de una beca posdoctoral otorgada por el Centro de Lingüística Hispánica del Instituto de Investigaciones Filológicas (IIFL) de la Universidad Nacional Autónoma de México. Realizó estudios de Arqueología Clásica en la Universitat Autònoma de Barcelona (2010) y cursó un máster en Educación en la Universidad Nacional de Educación a Distancia (2018). En la actualidad es investigadora del Centro de Estudios Clásicos del IIFL en donde desarrolla la investigación titulada "Colocaciones y verbos soporte en latín: estudio semántico y sintáctico de las construcciones con nombres predicativos. Manual introductorio de lingüística latina para estudiantes universitarios". Su trabajo está centrado en el estudio semántico, sintáctico y léxico de los verbos transitivos y, en particular, de aquellos que conforman colocaciones verbo-nominales tanto en la lengua latina como en las primeras etapas de las lenguas romances desde una perspectiva funcional y tipológica. 